\section{Federico Mayor Zaragoza, recibe Premio Derechos \\ Humanos de la Abogacía 2012}

\author{
Recibido: 17 de febrero de 2012/
}

Aprobado: 18 de febrero de 2012.

$\mathrm{F}$ ederico Mayor Zaragoza, la Corte Penal Internacional y la periodista Almudena Ariza han sido galardonados con los Premios Derechos Humanos de la Abogacía 2012, que concede en el Consejo General de la Abogacía Española a través de la Fundación Abogacía.

En su XIV Edición, el Jurado de los

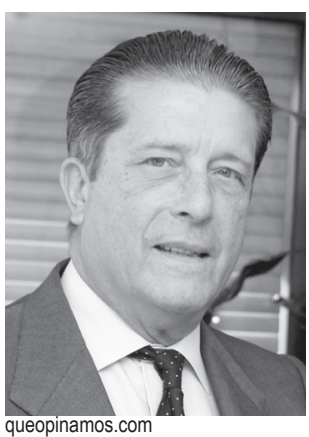

Premios Derechos Humanos ha concedido el premio en la categoría de "Personas" a Federico Mayor Zaragoza, ex director general de la UNESCO y actual presidente de la Fundación Cultura de Paz, por "su dilatada trayectoria en la defensa de los Derechos Humanos y contra la injusticia, de manera relevante". Con la Fundación para una Cultura de Paz, constituida en Madrid en marzo de 2000, continúa la labor emprendida como director general de la UNESCO de impulsar el tránsito de una cultura desde la violencia e imposición a una cultura de paz y tolerancia.

Además, la Corte Penal Internacional recibirá el Premio Derechos Humanos de la Abogacía en la categoría de "Instituciones", después de que en su primer fallo condenara a Thomas Lubanga, líder de los rebeldes del Congo por reclutar niños soldado y marcar así un prometedor precedente. Los jueces consideraron probado que forzó a menores de 15 años a luchar entre 2002 y 2003. Ocurrió en el conflicto armado paralelo desatado en la provincia de Ituri, al noreste del país. Para la Corte, abierta hace una década, supone un hito en su intento de erradicar una práctica que ha robado la infancia a miles de pequeños en Asia, África y América Latina. Los jueces fallaron por unanimidad. La Corte

\section{Estimado Profesor:}

Reciba en nombre de todo el equipo que integra el Instituto "Martin Luther King", de la Universidad Politécnica de Nicaragua (UPOLI), nuestras efusivas felicitaciones al otorgársele el Premio Derechos Humanos de la Abogacía 2012, que concede en el Consejo General de la Abogacía Española a través de la Fundación Abogacía. Este premio otorgado también a la Corte Penal Internacional y a la Sra. Almudena Ariza, enaltece y honra no sólo a los galardonados, que en su caso, es más que meritorio, sino también al organismo auspiciador, pues como dijo Martí: "Honrar, honra". Estamos seguros que nuevos reconocimientos están por venir a alguien que ha aportado tanto a la paz, a la justicia y a la libertad en el mundo ¡Albricias!

Afectuosamente,

Denis Torres

Director Instituto "Martin Luther King" - UPOLI

Penal Internacional, con sede en La Haya, es un tribunal de justicia internacional permanente cuya misión es juzgar a las personas acusadas de cometer crímenes de genocidio, de guerra y de lesa humanidad.

El Jurado ha concedido el premio en la categoría de "Medios de Comunicación" a la periodista Almudena Ariza, corresponsal de TVE en Asia-Pacífico, que en los últimos tiempos ha cubierto innumerables conflictos armados y catástrofes y ha llevado al conocimiento de todos los ciudadanos las peores tragedias informando sin protagonismo personal, con objetividad, con especial atención a los más débiles y utilizando las redes sociales, como en el caso del conflicto de Libia, cuando las circunstancias no permitían trasmitir por los cauces habituales. Según el jurado, "representa lo mejor de los valores periodísticos".

\section{Ceremonia de entrega}

En total se han presentado 61 candidaturas, 21 en la categoría de personas, 22 en la de instituciones y 18 en la de medios de comunicación. La ceremonia de entrega de galardones del XIV Premio Derechos Humanos de la Abogacía, tendrá lugar el 13 de diciembre en Madrid, en el transcurso de la Conferencia Anual de la Abogacía. 